Laser Chem. 1986, Vol. 6, pp. 291-305

0278-6273/86/0605-0291\$12.00/0

(c) harwood academic publishers $\mathrm{GmbH}$

Printed in Great Britain

\title{
PICOSECOND PROCESSES OF PHOTOSYNTHESIS IN LASER ABSORPTION STUDIES
}

\author{
A. Yu. BORISOV, A. P. RAZJIVIN \\ Department of Photosynthesis \\ A. N. Belozersky Laboratory \\ M. V. Lomonosov Moscow State University \\ 119899 MOSCOW, USSR \\ R. V. DANIELIUS, R. J. ROTOMSKIS \\ Laser Research Center of V. Kapsukas \\ Vilnius University \\ 232734 Vilnius, USSR
}

The demand for new energy sources has stimulated extended studies of sunlight energy conversion processes in photosynthesis. The primary photosynthetic processes are at present the basic field of research. These processes are characterized by high quantum efficiency, an important factor for designings artificial sunlight energy converters. Studying primary photosynthetic processes enables us to understand and model sun energy conversion.

The universally accepted scheme of photosynthetic primary processes includes: (i) absorption of a light quantum and further transfer of the electronically excited state (excitation) via pigment molecules of light harvesting antenna (LHA); (ii) excitation trapping by the reaction center (RC) and transformation of this energy into the energy of separated charges of different signs in RC.

The charge separation processes in RCs were studied almost exclusively by means of absorption laser picosecond spectroscopy (LPS) on isolated RC preparations ${ }^{1-5}$. Absorption LPS appeared to 
be the most appropriate for investigating these processes: RCs exhibit large photoinduced absorption changes while RC fluorescence is too weak for registration with an appropriate spectral and time resolution $^{6}$. On the other hand, many important aspects of excitation migration over LHA may be solved with the help of fluorescence. The intensity of fluorescence is proportional to the concentration of excited molecules. This makes it possible to observe excitation energy distribution over LHA as well as excitation migration via light harvesting pigments if ultrashort light pulses are used. The experimental data obrained in the 1960's by the phase-fluorometer method show that photosynthetic objects are characterized by longlived fluorescence ${ }^{7}$. But subsequent works showed that the main part of light harvesting pigment has a short-lived fluorescence with the time constant $\sim 30-100$ ps ${ }^{8,9}$. But these data, obtained with the modified phase-fluorometer method, had to be verified by more direct and informative methods.

The appearance of picosecond lasers and adequate registration instruments made direct measurements possible. The first picosecond fluorescence investigations indicated short-lived fluorescence 10-12. Yet subsequent measurements caused some doubts about the validity of the results: when the sample is excited by strong laser light pulses, non-linear effects may appear ${ }^{13-15}$. Some papers dealing with the problems of non-linear effect influence on natural photosynthesis were published ${ }^{16}$.

As noted above, primary light energy conversion in photosynthesis comprises the two main stages: the excitation transfer via LHA pigments toward RCs and the trapping and stabilization of this energy in RCs (electron transfer via RC molecules). Significant progress has been made in separate investigation of these two stages, but the problem of their coupling has received little attention so far. This is largely due to the absence of a unified approach to the investigation of these two stages. The low quantum 
yield of RC fluorescence $\left(\leqslant 10^{-3}\right)$, its spectral similarity to LHA fluorescence, on one hand, and the relatively low sensitivity of the absorption LPS method, on the other, hindered the coupling problem investigation by means of absorption and fluorescence LPS. The former difficulty is apparently of principal nature, while the latter one was overcome to some extent when a picosecond difference absorption spectrometer with the sensitivity better than $10^{-3}$ A-units and with selective excitation was designed ${ }^{17,18}$. Using absorption picosecond spectroscopy makes it possible to follow the time course of photoinduced absorption changes due to antenna molecules as well as the appearance of signals as a result of charge separation in RCs. Thereby we can discriminate between the kinetics of energy transfer from LHA to RCs and the multicomponent kinetics of excitation deactivation in LHA, and thus study the parameters of the process.

To investigate primary photosynthesis processes by picosecond absorption spectroscopy, one has to fulfill certain essential requirements: (i) selective excitation of photosynthetic preparation in visible and in near infrared spectral regions; (ii) high sensitivity for measuring small absorption changes in samples with the absorbance 1 A-unit; (iii) sufficiently low picosecond excitation pulses to exclude non-linear processes which may interfere with experimental results as strong laser pulses are used. The above listed requirements were fulfilled in a difference spectrophotometer with a picosecond time resolution which was developed on the basis of parametric picosecond light oscillators ${ }^{19,20}$.

Figure 1 presents the block scheme of a picosecond laser difference spectrophotometer. YAG: $\mathrm{Nd}^{3+}$ laser with passive mode-locking was used as a driving generator. A single pulse selected from a pulse train is amplified in a two-stage amplifier, then three beams are formed. The first beam, after its frequency has been 


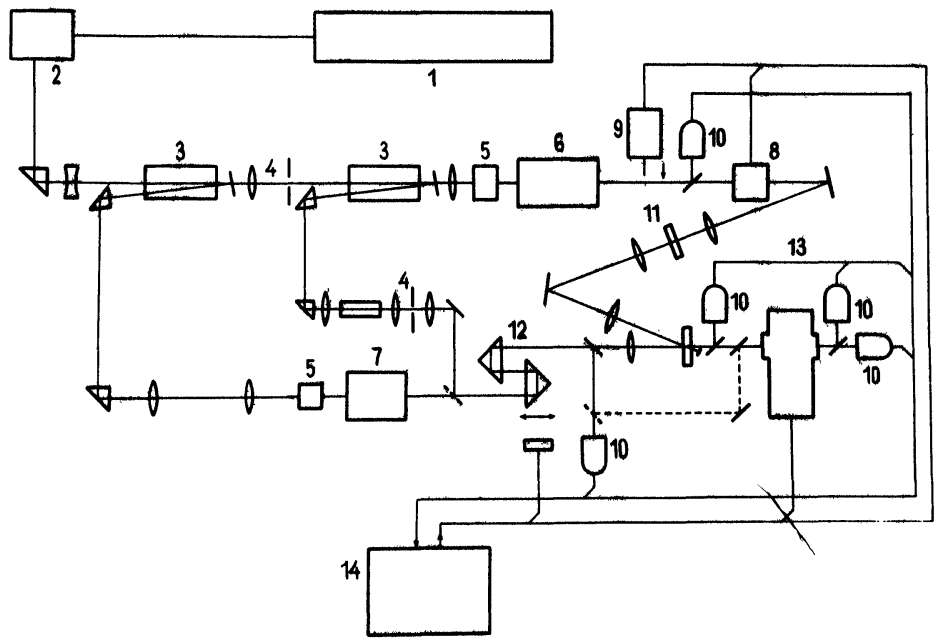

FIGURE 1 A block diagram of picosecond absorption spectrometer. 1 - picosecond YAG: $\mathrm{Nd}^{3+}$ laser, 2 - monopulse extraction scheme, 3 - YAG: $\mathrm{Nd}^{3+}$ two-stage amplifier, 4 - diaphragm, 5 - second harmonic generator, 6 - picosecond parametric oscillator of excitation channal, 7 - picosecond parametric oscillator of probing channel, 8 - attenuator (tuning optical filter), 9 - electromechanical shutter, 10 - photodetector, 11 - opal glass, 12 - time delay line, 13 - monochromator, 14 - registration and control arrangement with a micro-computer.

doubled, pumps an optical parametric oscillator (OPO) on KDP crystals, the second beam pumps OPO on the $\mathrm{LiNbO}_{3}$ crystal. The wavelength of excitation and probing beams is tuned continuously and 1ndependently in a $0.8-1.5 \mu \mathrm{m}$ spectral range, the pulse energy being 1-2 $\mathrm{mJ}$ for KDP OPO, and 0.7-2 $\mu \mathrm{m}$ and $0.05-0.1 \mathrm{~mJ}$ for LiMbo 3 OPO. The first beam is used for sample excitation, the second for absorption probing. An electromechanic shutter for measuring the zero level and an attenuator (a tuning optical filter) were put into the excitation beam. A picosecond continuum source on $D_{2} O$ pumped by the third beam of the main radiation was used for beam probing at difference spectrum measurements in a wide range. OPO 
was used to measure the dependences of absorption changes on excitation intensity and the kinetics of absorption changes. The application of considerable narrow-band radiation made it possible to dispense with a spectral device in the registration channel, and to use photodiodes as photoreceivers. As a result, a sencitivity of $>10^{-3}$ units could be obtained, the absorption being $\sim 1$ unit. The error level of the measurements was $2-3 \%$ if absorption changes were $5 \cdot 10^{-2}$ units. When probing was carried out by continuum, a typical measurement error was of $2-5 \cdot 10^{-3}$ units.

The time resolution of the spectrometer is up to $10 \mathrm{ps}$ when a single exponential process is recorded. When the relaxation process is more complicated, computer simulation is needed. The initial processing of the information and the operation on the spectrometer were carried out by a microcomputer "Electronica D3-28" through an individual interface.

We might just as well discuss the advantages of selective excitation and probing and, in particular, high sensitivity needed for photosynthetic studies. First, excitation in the long wavelength bacteriochlorophyll (BChl) band of LHA excludes all problems connected with energy transfer from additional pigments (carotenoids) to $\mathrm{BChl}$ (the efficiency of this process is $\sim 0.3$ and may vary). Second, one can achieve uniform excitation of the sample by excitation wavelength tuning. It is important because the relaxation of excitation in LHA depends on excitation intensity. For example, one can use chromatophore samples with high optical density at the absorption peak (up to 10 A-units) which makes it possible to obtain a high amplitude of the RC signal (up to 0.3 A-units). But this will be useful only if the selective probing at the band wings is available too. The high values of the ratio between the photoinduced RC signal and the initial absorption on the same wavelength are registered near $800 \mathrm{~nm}$ in the absorption band 


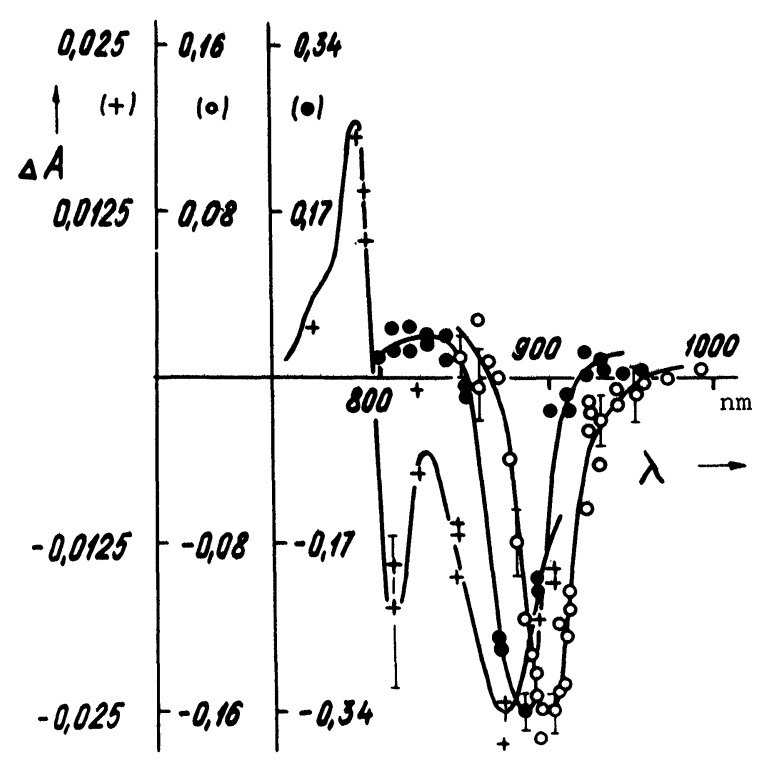

FIGURE 2 Difference spectra of photo-induced absorption changes in Rhodospirillum rubrum chromatophores at high (•) and low (O) intensities of exciting $900 \mathrm{~nm}$ light pulses $\left(>10^{16}\right.$ and $<10^{15}$ photon $/ \mathrm{cm}^{2}$, respectively). The probing pulse coincides in time with the arrival of the exciting one. The curve $(+)$ carried out at low $\left(<10^{15}\right.$ photon $/ \mathrm{cm}^{2}$ ) intensity of $915 \mathrm{~nm}$ picosecond pulses with 450 ps time delay for probing pulse relative to exciting pulse. Absorbance of chromatophores in a $1 \mathrm{~mm}$ cell at $880 \mathrm{~nm}$ was $\gtrsim 1 \mathrm{~A}$-unit.

of RC monomeric BChl of $\mathrm{R}$. rubrum and $\mathrm{R}$. sphaeroides chromatophores. The results given below show absorption changes due to oxidation of $\sim 10 \%$ RCs in chromatophores and corresponding to an excitation intensity of about 1 photon per 300-400 BChl molecules.

purple bacteria are the traditional object for photosynthetic studies, for their photocynthetic apparatus is simpler than that of higher plants and algae. Membrane preparations containing photosynthetic apparatus (chromatophores) may be extracted from purple bacteria cells by biochemical methods. These preparations are 


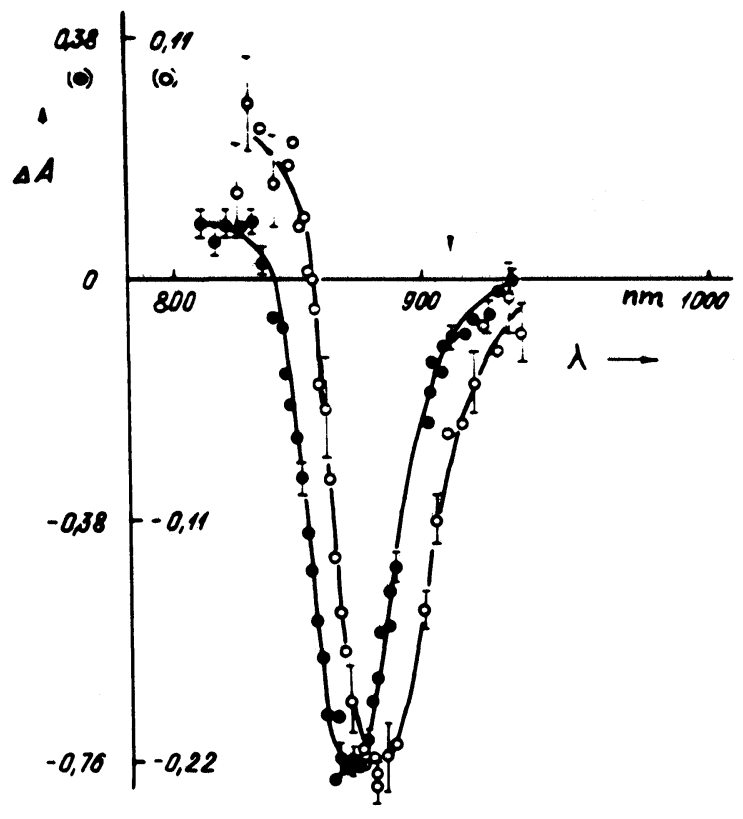

FIGURE 3 Difference spectra of photo-induced absoption changes in R. sphaeroides R-26 chromatophores at high (๑) and low (0) intensities of exciting $840 \mathrm{~nm}$ pulses $\left(>10^{16}\right.$ and $<10^{15}$ photon $/ \mathrm{cm}^{2}$, respectively). The probing pulse coincides in time with exciting one. Absorbance of the sample on the exciting wavelength was about $0.5 \mathrm{~A}$ units.

more adequate for optical investigations than suspensions of bacteria cells. Chromatophore membranes contain the pigment-protein complexes of RCs and LHA. Each pigment-protein complex contains some pigment molecules whose spatial arrangement is determined by special packing of the protein component 23,24 . The RC isolated from some purple bacteria may serve as an example of pigment-protein complex ${ }^{23}$. In turn, the LHA is assembled from dozed pigmentprotein complexes of one or more types, different from RC ${ }^{24-27}$. We investigated chromatophore preparations from purple photosynthetic bacteria Rhodospirillum rubrum, Rhodopseudomonas spha- 


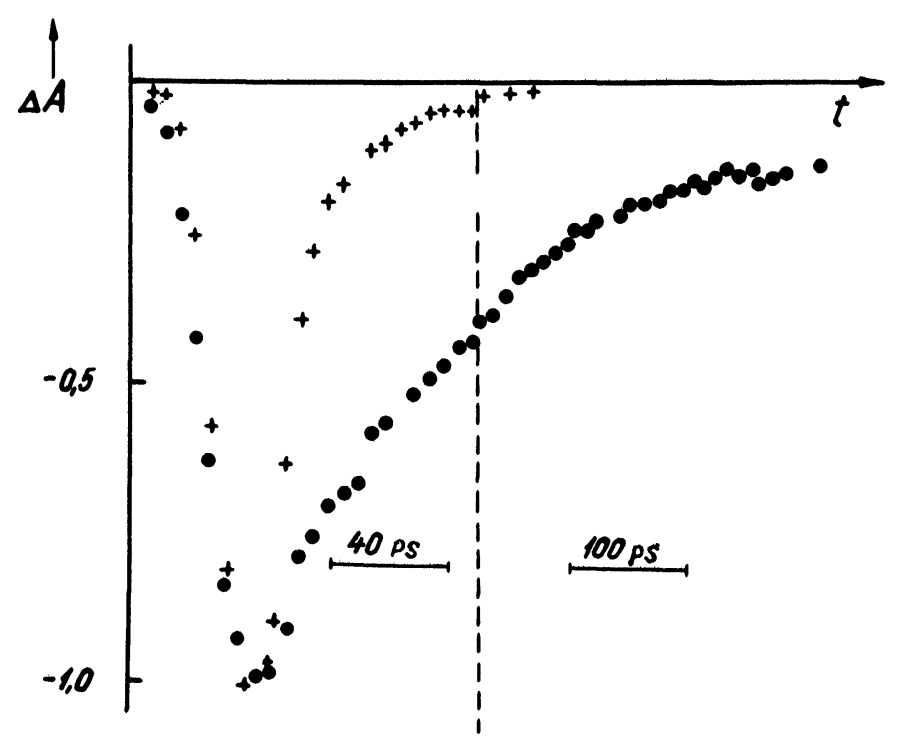

FIGURE $4 \mathrm{a}$ The kinetics of absorbance changes of $\mathrm{B}_{\mathrm{O}}$ and $\mathrm{B}_{\mathrm{m}}$ signals for complex B890 from C. minutissimum chromatophore. Curve $(+)$ recorded at $873 \mathrm{~nm}$ under $840 \mathrm{~nm} \mathrm{ex-}$ citation $\left(4.10^{16}\right.$ photon $\left./ \mathrm{cm}^{2}\right)$; curve (0) recorded at $900 \mathrm{~nm}$ under 840 excitation $\left(3 \cdot 10^{15}\right.$ photon $\left./ \mathrm{cm}^{2}\right)$; sample absorbance at $885 \mathrm{~nm}$ was about $1.5 \mathrm{~A}$ unit.

aeroides, strain R-26, Rhodopseudomonas viridis, and the pigmentprotein comlex B890 from Chromatium minutissimum. These 4 species represent sufficiently fully the entire suborder of purple bacteria. That is why the obtained picture of excitation transfer processes via LHA and excitation trapping by RCs in chromatophores, may be characteristic of the suborder of purple basteria as a whole.

Control experiments show a sufficiently high quality of chromatophore preparations. The number of LHA BChl molecules was about 30-35 per RC. The absolute quantum yield of RC oxidation in chromatophores due to continuous illumination was estimated at $0.87 \pm$ 0.15 . With the aid of the relative method of quantum yield estima- 


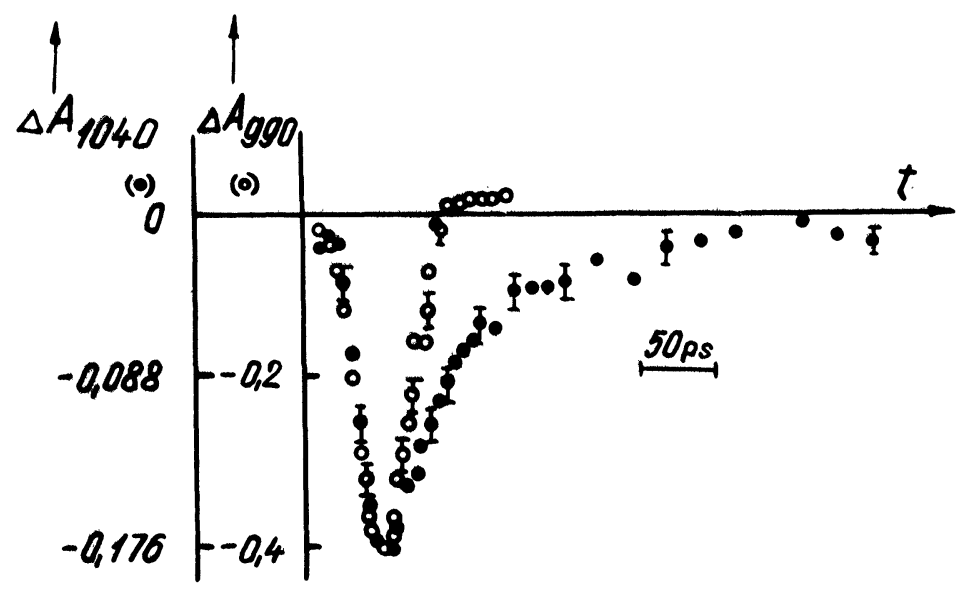

FIGURE 4b The kinetics of absorbance changes of $\mathrm{B}_{\mathrm{o}}$ and $\mathrm{B}_{\mathrm{m}}$ signals for $R$. viridis chromatophores. Both curves were registered by $930 \mathrm{~nm}$ exciting pulses with high $(\bullet)$ and low (O) intensity $\left(10^{14}\right.$ and $10^{16}$ photon $/ \mathrm{cm}^{2}$, resp.). $\operatorname{tion}^{21}$, which excludes the influence of destroyed and initially defected chromatophores, we obtained the value $0.90 \pm 0.03$.

It is accepted that the long-wavelength pigment-protein complex of LHA in chromatophores is represented only by one pigment spectral form $24,25,28$. In our experiments it was shown that spectral changes in LHA long-wavelength absorption band of purple bacteria chromatophores are of complex nature (Figures 2,3 ). These changes were interpreted as the manifestation of two spectral forms of LHA ${ }^{29-31}$. The following scheme of energy transfer from LHA to RC in bacterial photosynthesis as presented here is based on an analysis of spectral (Figures 2,3 ) and kinetic (Figure 4) data, as well as exciting pulse intensity dependences (Figures 5,6$)^{32-34}$ :

$$
\mathrm{B}_{\mathrm{O}} \longrightarrow \mathrm{B}_{\mathrm{m}} \longrightarrow \mathrm{RC}
$$

where $B_{0}$ - the bulk BChl of LHA, $B_{m}$ - the minor fraction of LHA localized in the vicinity of RC. 


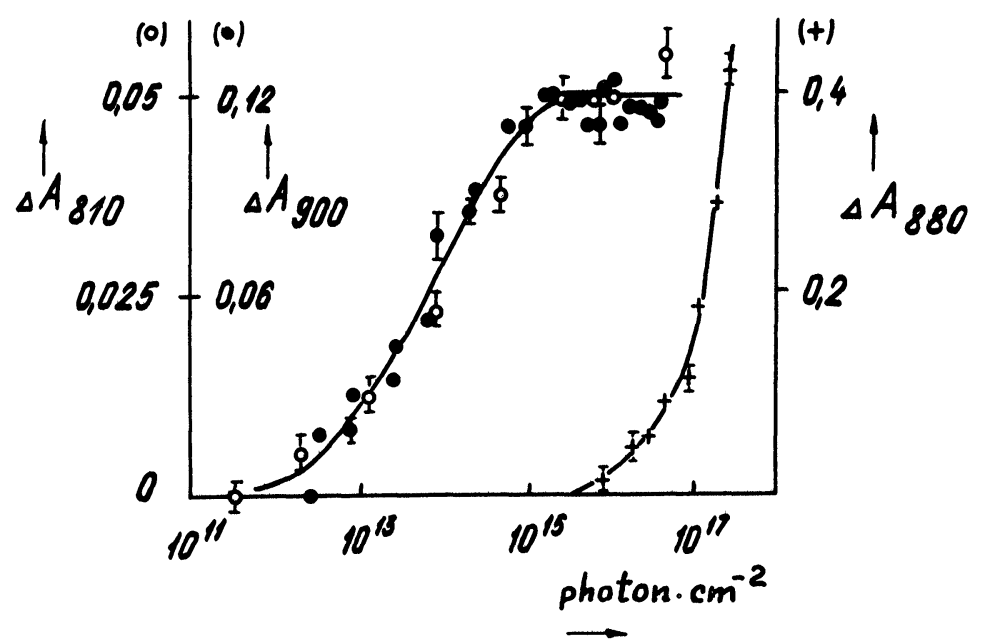

FIGURE 5 Dependence of absorption changes of R. rubrum chromatophores on the energy of 915 exciting pulses (light curves): curves $(+)$ and (o) were measured at $880 \mathrm{~nm}$ (in $\mathrm{B}_{\mathrm{O}}$ band) and $900 \mathrm{~nm}$ (in $\mathrm{B}_{\mathrm{m}}$ band), respectively; probing pulse coincided in time with the exciting one in both cases; curve (0) that corresponds to P800 band shift due to RC oxidation, was measured at $810 \mathrm{~nm}$ with 450 ps time delay for probing pulse relative to the exciting one.

The minor components of LHA, whose absorption bands are shifted of longer wavelengths compared to the RC absorption band, have been considered in works on plant photosynthesis (the components with a fluorescence maximum at $720-740 \mathrm{~nm})^{35}$. It is accepted that photoinduced excited states begin to leak to these forms at low temperatures due to inactivation of $\mathrm{RCs}^{36}$.

The long wavelength bleaching band in the difference picosecond spectrum of chromatophores was interpreted as a result of the transition of 3-5 highly interacting $\mathrm{BChl}$ molecules to an excited state. Moreover, it was proposed ${ }^{33,38}$ that all pigment molecules of the minor form $B_{m}$ comprise a structure similar to an associate 


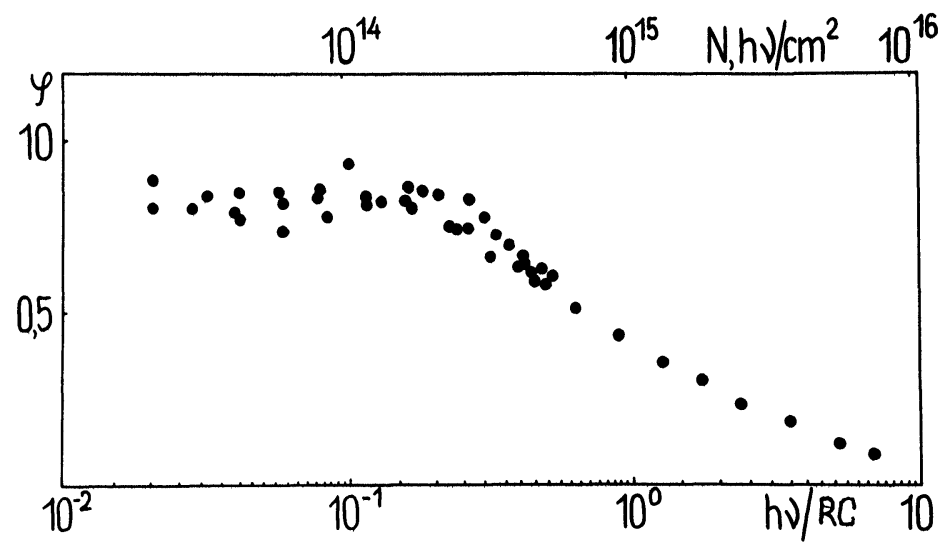

FIGURE 6 Dependence of the absolute quantum yield of RC photooxidation in $\mathrm{R}$. rubrum chromatophores on intensity of exciting pulses (for absorbed quanta only).

of dye molecules and that this associate is incorporated into a single pigment-protein complex. If this assumption is valid, such a pigment protein complex, in principle, may be purified from chromatophores of purple bacteria. Although the analysis of the LHA protein composition has yielded no minor polypeptides ${ }^{42}$, the LHA heterogeneity is indicated by the studies of $\mathrm{BChl}$ oxidation in $\mathrm{RC}$ deficient $R$. rubrum mutant ${ }^{39}$, by the low-temperature absorption spectra measurements 40 and by the fluorescence polarization spectra of chromatophores 41 .

At the present time it is not clear if the absorption changes found on the long wavelength side of the absorption band of IHA testify to LHA structural heterogeneity. For example, in ${ }^{37}$ it was suggested that as the antenna BChl dimer absorbs a light quantum, a mixing of the singlet excited state and the charge transfer state takes place in this dimer. The difference spectrum of the minor form corresponds to the absorption of the charge transfer state while the spectrum of the major form - to the absorption of 
the singlet excited state. The CT-state level is $\sim 30 \mathrm{meV}$ lower than the $S_{1}$ level. The logical suggestion is that the energy transfer to RC via antenna molecules may be connected with some kind of charge migration instead of singlet excited states migration. But this model fails to explain the behaviour of the light curves (Figure 5).

Yet there may be more involved interpretations of the difference spectrum $B_{m}$ as well. It has been shown that this spectrum can be well simulated by a bleaching of the main absorption band and by a short-wavelength shift of the same band. The absorption changes, which may be desribed in this way, are registered in some other objects with strong intermolecular interaction - dye aggregates $^{43}$, and polycrystals of $\mathrm{Chl} \mathrm{a}^{44}$. The absorption band shift may be of electrochromic nature as a result of charge separation in antenna, as suggested in 33,34. Evidence for such interpretation is the large amplitude of $B_{m}$ bleaching. A cross-section of $B_{m}$ molecule absorption is to be 3-fold higher than that of BChl dimers of LHA or RC if we want to obtain such an amplitude of $B_{m}$ bleaching.

According to new data obtained by absorption picosecond spectroscopy, the scheme of excitation transfer and trapping in chromatophores from photosynthetic bacteria differs from the traditional one. It is quite difficult to determine the influence of annihilation processes on the kinetics of absorption changes of LHA bacteriochlorophylls. The point is that an increase in exciting pulse intensity results in absorption band bleaching (Figure 4). But this bleaching is not manifested in low intensity excitation due to its rapid relaxation as compared with exciting and probing pulse duration ( $20 \mathrm{ps}$ ). The $\mathrm{B}_{\mathrm{m}}$ bleaching decay time hardly changes (Figure 6) for the broad exciting intensity range $\left(10^{14}\right.$ $10^{16}$ photon $/ \mathrm{cm}^{2}$ ) when the kinetics is on a fixed wavelength where 
only the $\mathrm{B}_{\mathrm{m}}$ signal appears. This "independence" may occur if the annigilation processes are very rapid and can be accomplished at the stage of excitation transfer $B_{0} \rightarrow B_{m}$. We believe that with the development of an universal laser spectrometer to take parallel absorption and fluorescent measurements in identical experimental conditions, it would become possible to make progress in solving this problem. On the other hand, we hope that the use of difference spectrophotometers with subpicosecond time resolution will open up new opportunities for a better understanding of energy migration and conversion in photosynthetic objects.

\section{REFERENCES}

1. T. L. NETZEL, P. M. RENTZEPIS, J. LEIGH, Science, 182, 238 (1973)

2. C. G. ROCKLEY, M. W. WINDSOR, R. J. COGDELL, W. W. PARSON, Proc. Natl. Acad. Sci. USA, 72, 2251 (1975)

3. P. L. DUTTON, K. J. KAUFMAN, B. CHANCE, P. M. RENTZEPIS, FEBS Letters, 60, 275 (1976)

4. S. L. SHAPIRO, A. J. CAMPILLO, in Ultrashort Light Pulses, edited by S. L. SHAPIRO (Springer Verlag, Berlin, 1977).

5. S. A. AKHMANOV, A. Yu. BORISOV, R. V. DANIELIUS, A. S. PISKARSKAS, V. D. SAMUILOV, A. P. RAZJIVIN, Pisma V JETF, 26, 655 (1977) (in Russian)

6. R. K. CLAYTON, Photosynthesis. Physical Mechanisms and Chemical Patterns (Cambridge Univ. Press, Cambridge, London, New York, New Rochelle, Melbourne, Sydney, 1980).

7. A. Yu. BORISOV, in Photosynthesis in Relation to Model Systems, edited by J. Barber (Biomedical Press, Elsevier/ North Holland, London, 1979), pp. 1-26.

8. A. Yu. BORISOV, M. D. IL'INA, Biokhimiya, 36, 822 (1971) (in Russian)

9. A. Yu. BORISOV, V. I. GODIK, Bioenergetics, 3, 211 (1972)

10. M. SEIBERT, R. R. ALFANO, S. L. SHAPIRO, Biochim. Biophys. Acta, 292, 493 (1973)

11. V. Z. PASCHENKO, A. B. RUBIN, Kvantovaya Electronika, 2 , 1336 (1975) (in Russian)

12. V. H. KOLLMAN, S. L. SHAPIRO, A. J. CAMPILLO, Biochim. Biophys. Res. Communs., 63, 917 (1975)

13. A. J. CAMPILLO, V. H. KOLLMAN, S. L. SHAPIRO, Science, 193, 227 (1976) 
14. D. MAUZERALL, Biophys. J., 16, 87 (1976)

15. G. E. SWENBERG, N. E. GEACINTOV, M. POPE, Biophys. J., 16, 1447 (1976)

16. J. BRETON, N. E. GEACINTOV, Biochim. Biophys. Acta, 594, 1 (1980)

17. R. DANIELIUS, A. PISKARSKAS, V. SIRUTKAITIS, A. STABINIS, J. YASEVICHUTE, Parametric Light Oscillators and Picosecond Spectroscopy (Mokslas, Vilnius, 1983), pp. 138-152 (in Russ.)

18. A. S. PISKARSKAS, in Laser Applications in Atomic, Molecular, and Nuclear Physics (MIR Publ., Moscow, 1979), pp. 249-313 (in Russian)

19. R. A. GADONAS, R. V. DANIELIUS, A. S. PISKARSKAS, Kvantovaya Elektronika, 8,669 (1981) (in Russian)

20. R. DANIELIUS, A. PISKARSKAS, V. SIRUTKAITIS, Kvantovaya Elektronica, 9 , 2491 (1982) (in Russian)

21. A. Yu. BORISOV, V. I. GODIK, S. G. FETISOVA, Molekularnaya Biologiya, 8, 458 (1974) (in Russian)

22. V. C. REMSEN, in The Photosynthetic Bacteria, edited by $R$. K. Clayton, W. R. Sistrom (Plenum Press, New York, London, 1978), pp. 31-60.

23. C. GINGRAS, in The Photosynthetic Bacteria, edited by R. K. Clayton, W. R. Sistrom (Plenum Press, New York, London, 1978), pp. 119- 131 .

24. J. P. THORNBER, R. J. COGDELL, B. K. PIERSON, R. E. SEFTOR, J. Cell Biochem., 23, 159 (1983)

25. R. PICOREL, G. BELANGER, G. GINGRAS, Biochemistry, 22, 2491 (1983)

26. K. SAUER, L. A. AUSTIN, Biochemistry, 17, 2011 (1978)

27. R. J. COGDELL, J. P. THORNBER, FEBS Lett. , 122, 1, (1980)

28. R. J. COGDELL, J. G. LINDSAY, J. VALENTINE, J. DURANT, FEBS Lett., 150, 151 (1982)

29. A, YU. BORISOV, R. A. GADONAS, R. V. DANIELIUS, A. S. PISKARSKAS, A. P. RAZJIVIN, S. G. KHARCHENKO, DOklady AN SSSR, 264,980 (1982) (in Russian)

30. J. A. ABDOURAKHAMNOV, R. V. DANIELIUS, A. S. PISKARSKAS, A. P. RAZJIVIN, R. J. ROTOMSKIS, in Abstracts of 6 Int. Congress on Photosynthesis, Brussels, 1,244 (1983)

31. R. V. DANIELIUS, V. V. KRASAUSKAS, R. J. ROTOMSKIS, in Studies in Spectroscopy and Quantum Electronics, VI (V. Kapsukas Vilnius Univ. Press, Vilnius, 1983), p. 95 (in Russ.).

32. A. P. RAZJIVIN, R. V. DANIELIUS, R. A. GADONAS, A. Yu. BORISOV, A. S. PISKARSKAS, FEBS Lett., 143, 40 (1982)

33. A. YU. BORISOV. R. A. GADONAS, R. V. DANIELIUS, V. S. KOZLOVSKI, A. S. PISKARSKAS, A. P. RAZJIVIN, S. G. KHARCHENKO, Doklady AN SSSR, 266, 482 (1982) (in Russian)

34. R. V. DANIELIUS, A. P. RAZJIVIN, Izvestiya AN SSSR, ser. fiz., 48,466 (1984) (in Russian) 
35. W. L. BUTLER, C. J. TREDWELI, R. MALKIN, J. BARBER, Biochim. Biophys. Acta, 545, 309 (1979)

36. V. Z. PASCHENKO, S. S. VASIL'EV, V. N. KORVATOVSKI, V. B. TUSOV, G. P. KUHARSKIN, A. B. RUBIN, Doklady AN SSSR, 273, 1252 (1983) (in Russian)

37. E. GAIZAUSKAS, G. TRINKUNAS, L. VALKUNAS, in Advance in Photosynthesis Research, edited by C. Sybesma (Martinus Nijhoff/ Dr. Junk publishers, Hague, 1984), Vol. 1, pp. 49-52.

38. A. Yu. Borisov, R. A. GADONAS, R. V. DANIELIUS, A. S. PISKARSKAS, A. P. RAZJIVIN, FEBS Lett., 138, 25 (1981)

39. J. GOMEZ, P. PICOREL, J.M. RAMIREZ, P. PEREZ, R. R. DEL CAMPO, Photochem. Photobiol., 35, 399 (1982)

40. F. F. LITVIN, B. A. GULYAEV, Izvestiya AN SSSR, ser. biol., 43 (1970) (in Russian)

41. H. KRAMER, Structural Aspects of Energy Transfer in Photosynthesis (Thesis, Leiden, 1984), p. 92.

42. R. A. BRUNISHOLZ, R. SUTER, H. ZUBER, Hoppe-Seyler's Z. Physiol. Chem. , 365, 675 (1984)

43. R. A. GADONAS, R. V. DANIELIUS, A. S. PISKARSKAS, S. RENCH, Izvestiya AN SSSR, ser. fiz., 47, 2445 (1983) (in Russian)

44. R. Danielius, R. GADONAS, P. MALIJ, Chem. Phys. Lett., (1985) (in press) 